\title{
Penile Mondor's disease: Imaging in two cases
}

\author{
Michele Foresti ${ }^{1 *}$, Andrea Parmiggiani ${ }^{1}$ \\ 1. Department of Diagnostic Imaging and Laboratory Medicine, Azienda USL-IRCCS di Reggio Emilia, Reggio Emilia, Italy \\ * Correspondence: Michele Foresti, Radiology Unit, C. Magati Hospital, Scandiano Viale Martiri della Libertà 6, 42019 Reggio Emilia, \\ Italy \\ $(\triangle$ Michele.Foresti@ausl.re.it)
}

Radiology Case. 2020 Dec; 14(12):24-30 :: $\quad$ DOI: $10.3941 /$ jrcr.v14i12.3926

\begin{abstract}
Penile Mondor's disease is a rare and under-recognized benign genital condition consisting of an isolated thrombosis of the dorsal superficial vein of the penis. Symptoms do not show distinctive features and there are asymptomatic cases. The patients usually present with a cord-like induration at dorsum of the penis. Diagnosis is usually made based on history and physical examination. The role of imaging in Mondor's disease is to identify the intravascular thrombus. In case of diagnostic uncertainty, Grey scale and Doppler ultrasound can be useful to detect the extent of thrombosis demonstrating echogenic material within venous lumen, vessel incompressibility and absence of flow, as well as painful selective pressure. The use of Magnetic Resonance imaging is controversial and not used routinely. Usually treatment is conservative: sexual rest, local anesthetics, anti-inflammatories, antibiotics in case of infection and anticoagulants. Sclerosing lymphangitis and Peyronie's disease have been described as possible differential diagnosis.
\end{abstract}

\section{CASE REPORT}

\section{CASE REPORT}

Patient 1: a 46-year-old man presented with complaints of penile pain during sexual intercourse, and he had experienced this pain for several weeks. There was no evidence of penile discharge, hematuria, dysuria, fever or erectile dysfunction, and he denied any recent vigorous sexual activity or a history of any type of trauma. His medical history was unremarkable, and he denied ever being infected with a sexually transmitted disease. On physical examination, a cord-like induration was palpated in the dorsal aspect of the penis not identified by family doctor during physical examination a few days before, and this was associated with tenderness and overlying skin erythema. There were no palpable lymph nodes in his groin. The patient came to our attention to perform an ultrasound exam prescribed by family doctor in order to rule out an inguinal hernia or testicular pathologies. Ultrasound of the penis using a Philips iU22 machine, with a high frequency linear probe (L15-5) on the small parts setting, demonstrated a non-compressible superficial dorsal vein with internal echogenicity. Color Doppler ultrasound demonstrated a lack of endoluminal flow signals (Figures 1,2,3). In consideration of the relative rarity of this finding, the limited clinical knowledge of the operator with this pathology and the desire to exclude other pathologies of the pelvic region, a pelvic basal CT scan was performed in order to have a greater diagnostic confidence. The CT examination showed a cordlike hyperdense thickening in the dorsal subcutaneous soft tissues of the penis corresponding to the thrombosis of the respective vein. Faded surrounding edema was associated (Figure 4). All other findings were unremarkable. Sexual abstinence, heparin ointment, and oral non-steroidal anti- 
inflammatory drugs (NSAIDs) were adopted as conservative therapy and patient recovered totally in 4-5 weeks.

Patient 2: a 51-year-old man came to our observation for the execution of an ultrasound examination of the penis in the suspicion of Peyronie's disease, complaining of pain during erections and a slight degree of dorsal curvature of the penis itself. A few months before the patient had been operated laparoscopically on the right kidney for an exophytic clear cell tumor. All other clinical findings were unremarkable. Ultrasound of the penis using a Philips iU22 machine with a high frequency linear probe (L17-5) on the small parts setting, demonstrated a non-compressible superficial dorsal vein with internal echogenicity and Color Doppler ultrasound demonstrated a lack of endoluminal flow signals (Figure 5). Sexual abstinence, heparin ointment, and oral non-steroidal anti-inflammatory drugs (NSAIDs) were adopted as conservative therapy and patient recovered totally in 2 months.

\section{DISCUSSION}

Mondor's disease is a thrombophlebitis of the superficial veins and was first defined by Henri Mondor in the superficial veins of the chest wall in 1939. In 1955, Braun-Falco defined dorsal phlebitis of the penis in the context of generalized phlebitis [1]. Isolated thrombosis of the dorsal superficial vein of the penis was first reported by Helm and Hodge in 1958 [2].

\section{Etiology \& Demographics:}

Penile Mondor's disease (PMD) is a rare and underrecognized benign genital condition. Its real incidence is considered to be higher than reported. Penile Mondor's disease affects sexually active men of any age. Age of the patients ranges between 18 and 70. No specific etiology has been found in the cases reported so far [1]. Previous reports of PMD assert an estimated incidence of approximately $1.39 \%$ and little more than 50 cases reported in the literature. While it can affect men of any age, usually, men at 20 to 40 years of age are at the highest risk. Studies have found that the risk factors of PMD fit Virchow's triad. The first risk factor of this triad can be a vessel wall damage, for example due to vigorous sexual activity, vacuum erection device, penile trauma, endovenous drugs abuse, pelvic or genital surgery. The second is blood stasis, such as prolonged erection (including with the use of a PDE5 inhibitor), prolonged sitting position, bladder overdistension, pelvic tumors like bladder or prostate cancer. The third cause can be hypercoagulation, such as urogenital infection, prostate biopsy, and hematological disease like thrombophilic states [3,4]. Moreover, deficiencies of antithrombin III, protein $\mathrm{C}$, and protein $\mathrm{S}$ can be considered risk factors for idiopathic penile venous thrombosis [5].

\section{Clinical \& Imaging findings:}

Even if sometimes PMD do not show distinctive features and can be asymptomatic, more often patients present with a cord-like induration at dorsum of the penis. They complain of episodic or continuous pain and throbbing. Erythema and edema may be seen on the penile skin. Some patients feel distention on the site of thrombosis. Pain is typically exacerbated during erection. There are three phases: acute, subacute and chronic. Acute period happens in the first 24 hours following a prolonged sexual intercourse and is possibly due to a traumatic injury of vascular endothelium (since histologically they have been detected changes in vascular walls, with narrowing, prominent endothelia and lymphoplasmocytic cells), clinical manifestations remain attenuated during subacute phase, and there is a spontaneous resolution in 6-8 weeks, with an average symptomatic period of 2,3 weeks [4].

Diagnosis is usually made based on history and physical examination. The role of imaging in Mondor's disease is to identify the intravascular thrombus. Grey scale and Doppler ultrasound can be useful in case of diagnostic uncertainty, to detect the extent of thrombosis demonstrating echogenic material within venous lumen, vessel incompressibility and absence of flow, as well as painful selective pressure. The caliber of the vein can be increased and present inflammatory changes in the wall. Some authors have reported a decrease in cavernous artery flow, with a low peak systolic velocity and high resistance $[4,5,6,7,8]$. Doppler and ultrasound can be also used for follow-up, showing the recanalization of the endoluminal thrombosed vein after the total recovery of the patient [9]. Patients should not be exposed to diagnostic penile Doppler ultrasound with an intracavernosal vasoactive agent injection, as this is unnecessary and has the potential to cause serious harm, like priapism [10].

Cases diagnosed with Magnetic Resonance Angiography (MRA) have been reported in the literature, but it is not used routinely in diagnosis and differential diagnosis of Mondor's disease. History and physical examination is of primary importance in the diagnosis, Color Doppler ultrasound may be used when necessary, but role of MRI is controversial [1,11]. The signal intensity of venous thrombosis on T1- and T2weighted MRI varies according to the time delay between the onset of thrombus formation and imaging. In the acute stage (0-5 days), with respect to the femoral vein, the signal intensity is predominantly isointense on T1-weighted images and hypointense on T2-weighted images. On the other hand, in the subacute stage (6-15 days), the signal intensity is described as predominantly hyperintense on both T1- and T2weighted images, and finally, the signal intensity in a chronic thrombus is typically isointense on T1-weighted and isointense or hyperintense on T2-weighted images. Moreover, by a 3D fast gradient-echo dynamic investigation a filling defect of the vein can be clearly visible $[6,11]$. MRA reveals the larger picture of the vein system. It may be helpful in certain situations, such as in cases of PMD after a prostate biopsy in order to eliminate the possibility of hematoma or an iatrogenic lesion [11].

The use of CT is not indicated for the diagnosis of PMD and to date there are no cases described in literature in which this method has been used for a diagnosis, even because it requires exposure to ionizing radiation. In our case the basic CT aspect of PMD consists of thickening and hyperdensity of the dorsal vein, associated with heterogeneous relative hyperdensity of the adjacent subcutaneous tissue due to edema. 
There are no typical changes in the serum and laboratory investigations showing tendency to thrombosis are rarely required. Systemic tests such as Anti-thrombin III, deficiency of Protein $\mathrm{C}$ and Protein S, MTFR gen defect, and assays for thrombophilia are more valuable in the cases of widespread thrombophlebitis [1].

\section{Treatment \& Prognosis:}

Several methods of treating penile Mondor's disease have been proposed, none of which has been shown to significantly decrease disease duration. Anticoagulation with heparin, aspirin, or other antiplatelet agents will not expedite healing and is not necessary to prevent additional thrombosis. Currently, treatment is pain relief for most patients. However, antibiotic therapy should be administered when cellulitis is suspected, and vein stripping may be necessary for severe, persistent cases of Mondor's disease. Injection of $0.5 \%$ bupivacaine hydrochloride subcutaneously in the region surrounding the affected vein has provided relief to patients who are in acute pain. Non-steroidal anti-inflammatory drugs have been used in an effort to dampen the inflammatory component of the phlebitis and provide pain relief for the patient. Physicians should emphasize with such patients the need to eliminate risk factors to help prevent recurrent episodes. Any object that rests on the suprapubic region, for example, should be avoided. Tool belts, money belts, and electric guitars are just a few examples. Patients also should avoid sexual devices or practices that are capable of causing venous stasis and injury to the penis [12].

Penile Mondor's disease is a rare and self-limiting condition. The most common cause is considered to be trauma due to vigorous and prolonged sexual intercourse. The condition is self-limiting within 4-6 weeks with the vessel regaining permeability in 9 weeks [8].

\section{Differential Diagnosis:}

Sclerosing lymphangitis and Peyronie's disease have been described as possible differential diagnosis of penile Mondor's disease.

Sclerosing lymphangitis appears acutely from several hours to two days after the incriminated sexual activity, presenting clinically as a hard cordon, straight or serpiginous (worm-like aspect), translucent, with a length of $1 \mathrm{~cm}$ to $4 \mathrm{~cm}$ located below and parallel to the balanopreputial furrow, most often in the dorsal part of the penis. The cordon is mobile and non-adherent to the overlying skin, with no signs of inflammation. Occasionally slight edema of the inner foreskin can be noticed. The lesion is asymptomatic, but sometimes can be accompanied by painful erections. The morphology of sclerosing lymphangitis is serpiginous and it is characterized by thickened and dilated lymphatic vessels not associated to dorsal vein thrombosis at ultrasonography.

Peyronie's disease results from a thickening of the tunica albuginea and presents as a well-defined immobile fibrotic plaque on the penis sometimes partially calcified [10,13,14]. Ultrasound has $100 \%$ sensitivity in detection and measurement of gross calcifications. MRI imaging is at least as sensitive as ultrasonography in demonstrating extension of plaques and their relationships with adjacent structures. On T1- and T2weighted images plaques appear as thickened and irregular low-signal intensity areas in and around tunica albuginea. According to some authors, enhancement of the plaques and of surrounding tissues after intravenous administration of gadolinium contrast material offers information about the presence of active inflammation. However, this statement has not been substantiated in recent studies. In fact, in clinical practice gadolinium enhanced MR imaging is not widely used to evaluate patients with Peyronie's disease.

In conclusion, differential diagnosis is based on the clinical history and physical examination while the gold standard for imaging is Doppler ultrasonography which, in Peyronie's disease, identifies the area of the thrombus, its extension, and the unambiguous signs of thrombosis: a noncompressible dorsal vein with venous flow absence. Other second level more expensive exams such as CT and MRI are not necessary for the diagnosis of this disease, unless they serve to rule out other etiopathogenetic causes in different body districts such as tumors, trauma or thrombosis of other vessels suggesting thrombophilia. [15-16].

\section{TEACHING POINT}

Penile Mondor's disease is a rare and under-recognized benign genital condition consisting of an isolated thrombosis of the dorsal superficial vein of the penis. The patients usually present with a cord-like hardness at the dorsum of the penis. Diagnosis is usually made based on history, physical examination and Color-Doppler ultrasound. This disease is usually self-limiting and conservative treatment is the therapy of choice.

\section{REFERENCES}

1. Ozturk H. Penile Mondor's disease. Basic Clin Androl. 2014 Mar 3;24:5. eCollection 2014. PMID: 25780580.

2. Helm JD Jr, Hodge IG: Thrombophlebitis of a dorsal vein of the penis: report of a case treated by phenylbutazone (Butazolidin). J Urol 1958,79:306-307.PMID: 13514882.

3. Amano M, Shimizu T. Mondor's disease: A review of the Literature. Intern Med. 2018 Sep 15;57(18):2607-2612. Epub 2018 May 18. PMID:29780120.

4. Machan K, Rojo-Carmona LE, Marquez-Moreno AJ et al. Ultrasound diagnosis of three cases of Mondor's disease. Arch. Esp. Urol. 2012; 65 (2): 262-266.

5. Conkbayr I, Yanik B, Keyik B et al. Superficial dorsal penile vein thrombosis (Mondor disease of the penis) involving superficial external pudendal vein: color Doppler sonographic findings. J Ultrasound Med. 2010 Aug;29(8):1243-5. PMID: 20660460.

6. Kantarci UH, Dirik A, Ozturk YE et al. Doppler Ultrasound and Magnetic Resonance Imaging findings of Penile Mondor's 
Disease: Case report and Literature Review. Pol J Radiol. 2016 feb 2;81:36-8. PMID: 26893793.

7. Han HY, Chung DJ, Kim Kw et al. Pulsed and color Doppler sonographic findings of penile Mondor's disease. Korean J Radiol. 2008 Mar-Apr;9(2):179-81. PMID: 18385566.

8. Mukendi AM, Mahlobo F. Penile Mondor's disease: Clinical and sonographic images. Clin case Rep. 2019 Oct 7;7(11):2283-2284. PMID: 31788306.

9. Outtara A, Parè AK, kaborè AF et al. Subcutaneous Dorsal Penile Vein Thrombosis of Penile Mondor's Disease: A case report and Literature review. Case Rep Urol. 2019 Aug 20; 2019:1297048. PMID: 31531260.

10. Polat H, Yucel MO, Gok A et al. Penile Mondor's Disease: Primum Non Nocere!. Urol J. 2015 Apr 29,12(2).2096-8. PMID: 25923155.

11. Boscolo-Berto R, Iafrate M, Casarrubea G et al. Magnetic resonance angiography findings of penile Mondor's disease. $\mathrm{J}$ Magnet Reson Imaging. 2009 Aug;302(2):407-10. PMID: 19629969.

12. Griger DT, Angelo TE, Grisier DB. Penile Mondor's disease in a 22-year-old man. J Am Osteopath Assoc. 2001 Apr;101(4):235-7. PMID: 11370549.

13. Kalokairininou K, Konstantinidis C, Domazou M et al. US Imaging in Peyronie's Disease. J Clin Imaging Sci. 2012;2:63. PMID: 23230545.

14. Ramos Baselò E, Portillo Martin JA, Correas Gomez M et al. Enfermedad de Mondor versus Linfagitis esclerosante de pene. Arch.Esp.Urol; 61,7(837-840),2008.

15. Linden-Castro E, Pelayo-Nieto M, Ramirez Galindo I et al. Mondor disease: thrombosis of the dorsal vein of the penis. Urol Case Rep 2018 May 5;19:34-35. PMID:29888185.

16. Bertolotto M, Pavlica P, Serafini G et al. Painful penile induration:imaging findings and management. Radiographics.2009 Mar-Apr;29(2):477-93. PMDI:19325060.

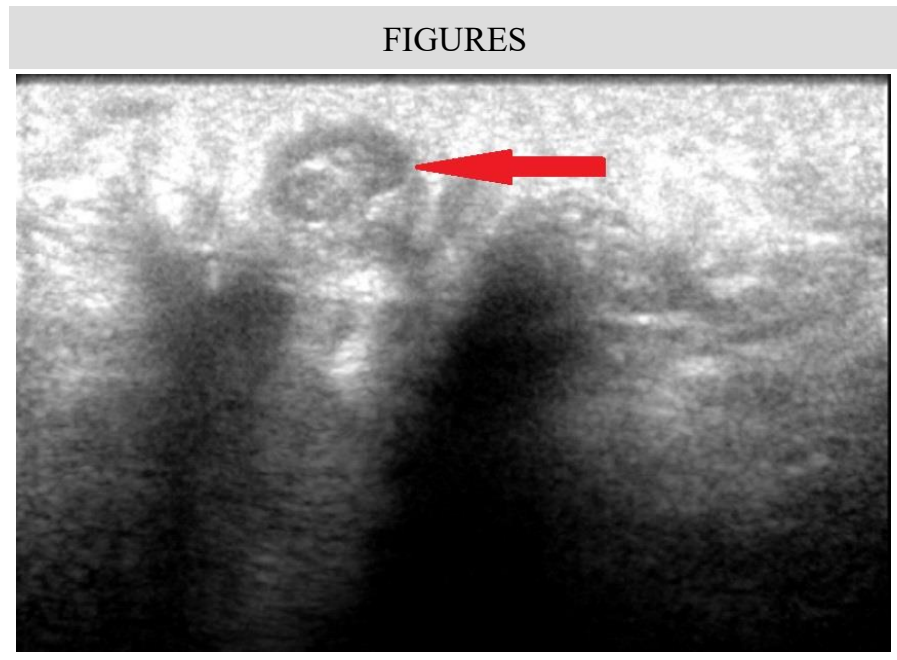

Figure 1: 46-year-old man with penile Mondor's disease. Findings: transverse gray scale ultrasound of the dorsal vein of the penis showing an endoluminal echogenicity consisting with the thrombus (red arrow). Clot with $7 \times 4 \mathrm{~mm}$ thickness and 30mm length.

Technique: Philips iU22 Ultrasound Machine. L17-5 MHz linear probe.

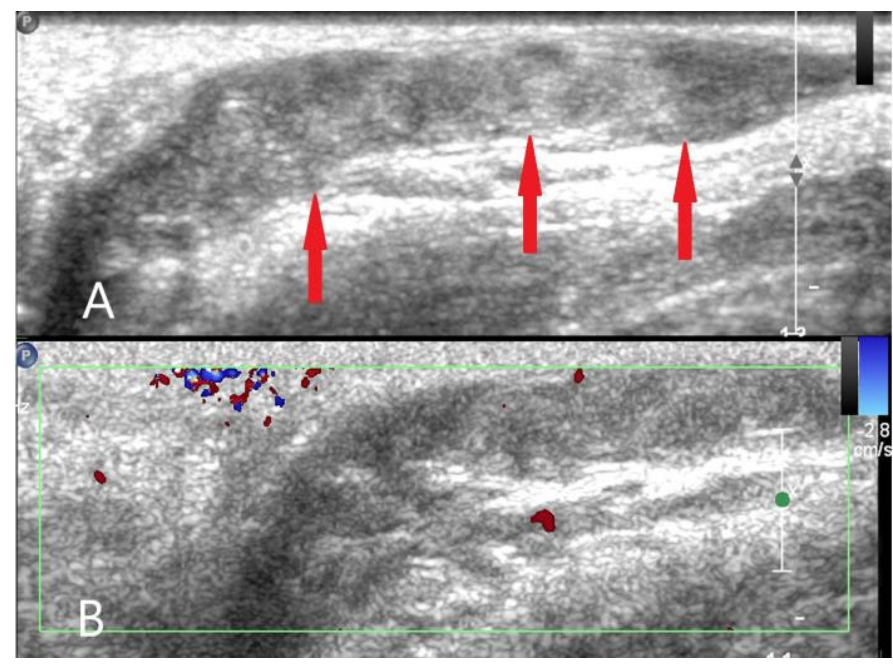

Figure 2: 46-year-old man with penile Mondor's disease.

Findings: longitudinal gray scale ultrasound of the dorsal vein of the penis showing an endoluminal echogenicity consisting with the thrombus (red arrow in A). Longitudinal ColorDoppler Ultrasound showing the absence of vascular flow signals within the dorsal vein of the penis (B).

Technique: Philips iU22 Ultrasound Machine. L17-5 MHz linear probe. 


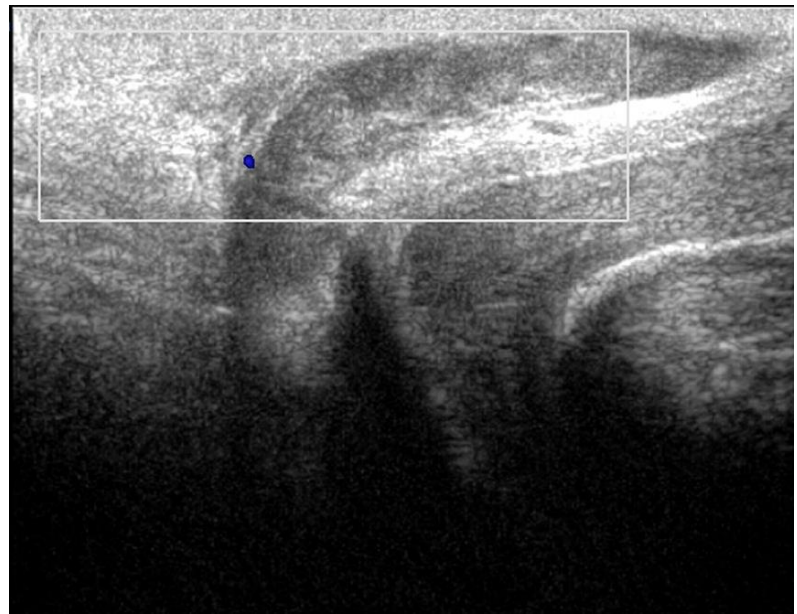

Figure 3 (top): 46-year-old man with penile Mondor's disease.

Findings: more panoramic longitudinal view Color-Doppler Ultrasound showing the absence of vascular flow signals within the dorsal vein of the penis.

Technique: Philips iU22 Ultrasound Machine. L17-5 MHz linear probe.

Figure 5 (right): 51-year-old man with penile Mondor's disease.

Findings: longitudinal (A) and transverse (B) gray scale ultrasound of the dorsal vein of the penis showing an endoluminal echogenicity consisting with thrombus (red arrows). Color Doppler ultrasound shows lack of vascular flow signals within the thrombosed dorsal vein (C). Clot with $4 \times 3 \mathrm{~mm}$ thickness and $28 \mathrm{~mm}$ length.

Technique: Philips iU22 Ultrasound Machine. L17-5 MHz linear probe.
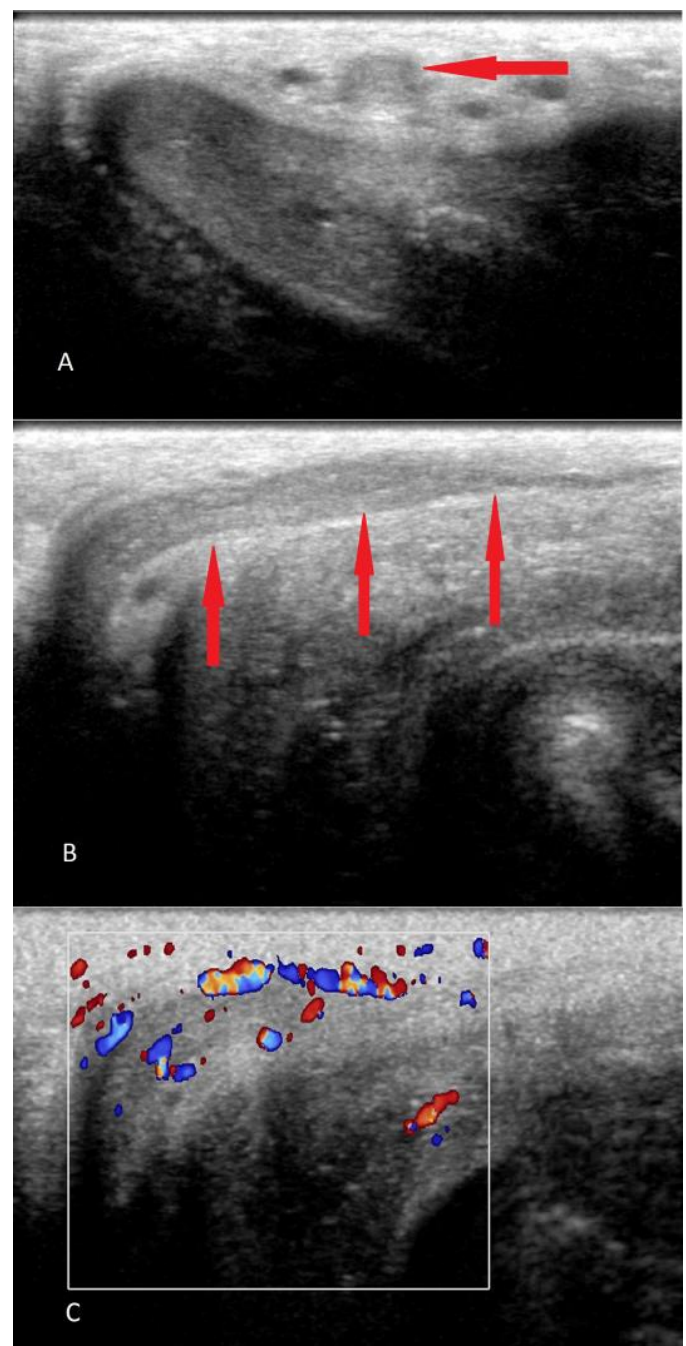
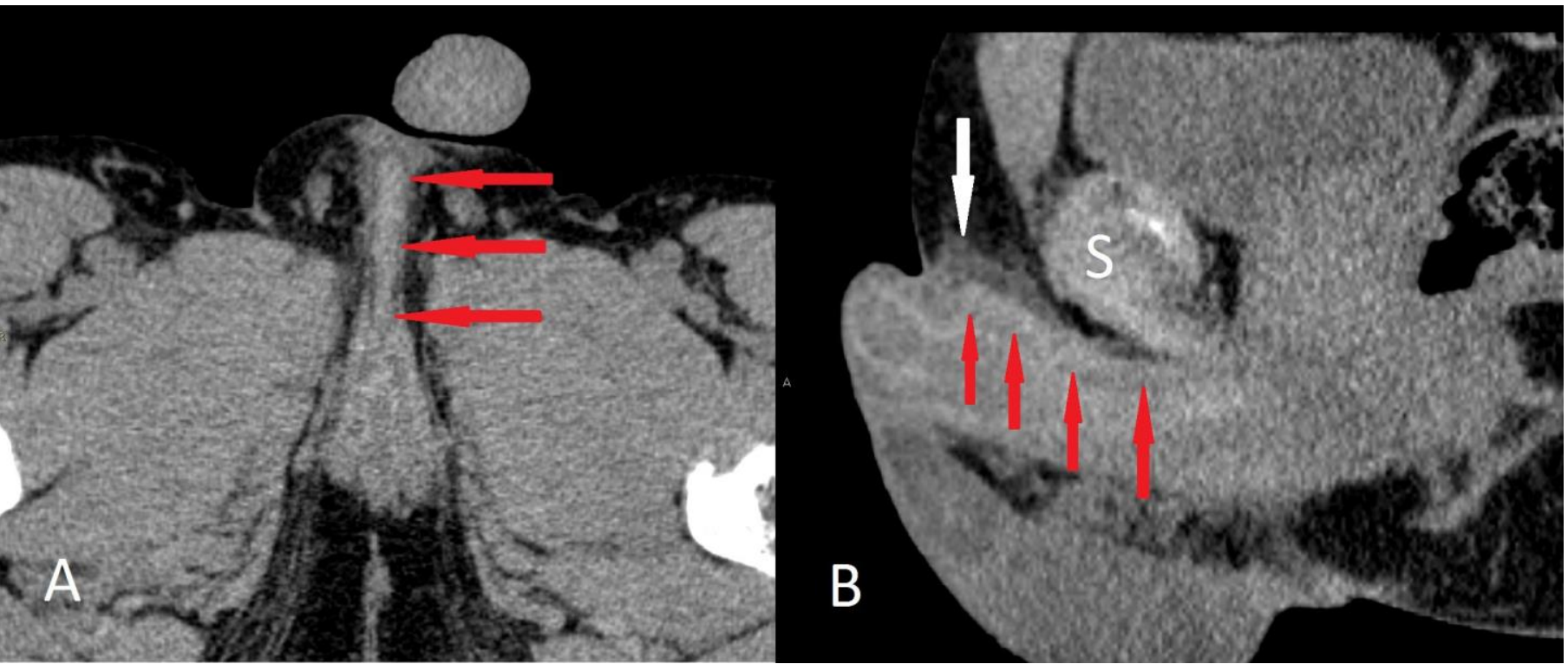

Figure 4: 46-year-old man with penile Mondor's disease.

Findings: axial (A) and sagittal (B) CT series showing a hyperdense dorsal vein of the penis consisting with endoluminal thrombosis (red arrows) and edema of the surrounding soft tissues (white arrow). S: pubic symphysis.

Technique: Somatom Emotion 16 slice scanner, Siemens Medical Solutions, Forchheim, Germany. CARE Dose for automatic exposure control for tube voltage $(\mathrm{kV})$ and effective tube current $(\mathrm{mA})$, slices acquired with $3 \mathrm{~mm}$ slice thickness, 1 pitch, and 0.6 second rotation time. 


\begin{tabular}{|c|c|c|c|c|}
\hline & Physical examination & $\begin{array}{l}\text { Color-Doppler- } \\
\text { Ultrasound }\end{array}$ & CT & MRI \\
\hline $\begin{array}{l}\text { Penile } \\
\text { Mondor's } \\
\text { disease }\end{array}$ & $\begin{array}{l}\text { - Cord-like induration at } \\
\text { dorsum of the penis. } \\
\text { - Episodic or continuous } \\
\text { pain and throbbing. } \\
\text { - Erythema and edema may } \\
\text { be seen on the penile skin. } \\
\text { - Pain typically exacerbated } \\
\text { during erection. }\end{array}$ & $\begin{array}{l}\text { - Echogenic material } \\
\text { within venous lumen. } \\
\text { - Impossibility of vessel } \\
\text { compression and } \\
\text { absence of flow. } \\
\text { - Painful selective } \\
\text { pressure. } \\
\text { - The caliber of the vein } \\
\text { can be increased and } \\
\text { present inflammatory } \\
\text { changes in the wall. }\end{array}$ & $\begin{array}{l}\text { - Not indicated. } \\
\text { Basal CT: } \\
\text { thickening and } \\
\text { hyperdensity of } \\
\text { the vein, } \\
\text { associated with } \\
\text { edematous } \\
\text { hyperdensity of } \\
\text { the adjacent } \\
\text { subcutaneous } \\
\text { tissue. }\end{array}$ & $\begin{array}{l}\text { - Role is controversial. The } \\
\text { signal intensity of venous } \\
\text { thrombosis varies } \\
\text { according to the time } \\
\text { delay between the onset } \\
\text { of thrombus formation } \\
\text { and imaging. } \\
\text { - In the acute stage (0-5 } \\
\text { days): isointense on T1- } \\
\text { weighted images and } \\
\text { hypointense on T2- } \\
\text { weighted images. } \\
\text { - In the subacute stage (6- } \\
\text { 15 days): hyperintense on } \\
\text { both T1- and T2- } \\
\text { weighted images. } \\
\text { - Chronic thrombus: } \\
\text { isointense on T1- } \\
\text { weighted and isointense } \\
\text { or hyperintense on T2- } \\
\text { weighted images. } \\
\text { In a 3D fast gradient- } \\
\text { echo dynamic } \\
\text { investigation a filling } \\
\text { defect of the vein can be } \\
\text { visible. }\end{array}$ \\
\hline $\begin{array}{l}\text { Sclerosing } \\
\text { lymphangitis }\end{array}$ & $\begin{array}{l}\text { - Hard cordon, straight or } \\
\text { serpiginous below and } \\
\text { parallel to the } \\
\text { balanopreputial furrow. } \\
\text { - The cordon is mobile and } \\
\text { non-adherent to the } \\
\text { overlying skin, with no } \\
\text { signs of inflammation. } \\
\text { - Occasionally slight edema } \\
\text { of the inner foreskin. } \\
\text { - Asymptomatic, but } \\
\text { sometimes accompanied } \\
\text { by painful erections. }\end{array}$ & $\begin{array}{l}\text { - The morphology of } \\
\text { sclerosing lymphangitis } \\
\text { is serpiginous with } \\
\text { thickened and dilated } \\
\text { lymphatic vessels. } \\
\text { - Usually not associated } \\
\text { to dorsal vein } \\
\text { thrombosis. }\end{array}$ & Not indicated & Not indicated \\
\hline $\begin{array}{l}\text { Peyronie's } \\
\text { disease }\end{array}$ & $\begin{array}{l}\text { - Most frequent cause of } \\
\text { painful penile induration. } \\
\text { - Deformity and shortening } \\
\text { of the penis. } \\
\text { - Palpable albugineal } \\
\text { plaque. }\end{array}$ & $\begin{array}{l}\text { Thickening of the tunica } \\
\text { albuginea. } \\
\text { - Well-defined immobile } \\
\text { fibrotic plaque on the } \\
\text { penis sometimes } \\
\text { partially calcified. }\end{array}$ & Not indicated & $\begin{array}{l}\text { - Not widely used in } \\
\text { clinical practice. } \\
\text { - T1-T2w: plaques appear } \\
\text { as thickened and irregular } \\
\text { low-signal intensity areas } \\
\text { in and around tunica } \\
\text { albuginea. } \\
\text { - Enhancement of the } \\
\text { plaques and of } \\
\text { surrounding tissues offers } \\
\text { information about the } \\
\text { presence of active } \\
\text { inflammation. } \\
\end{array}$ \\
\hline
\end{tabular}

Table 1: Differential diagnosis table for penile Mondor's disease. 


\begin{tabular}{|c|c|}
\hline Etiology & $\begin{array}{l}\text { Risk factors of PMD fit Virchow's triad, as follows: } \\
\text { - Vessel wall damage: vigorous sexual activity, vacuum erection device, penile trauma, endovenous } \\
\text { drugs abuse, pelvic or genital surgery. } \\
\text { - } \text { Blood stasis: prolonged erection (including with the use of a PDE5 inhibitor), prolonged sitting } \\
\text { position, bladder over-distension, pelvic tumors like bladder or prostate cancer. } \\
\text { - Hypercoagulation: urogenital infection, prostate biopsy, thrombophilic states. } \\
\text { - For idiopathic penile venous thrombosis, deficiencies of antithrombin III, protein C, and protein. }\end{array}$ \\
\hline Incidence & Rare and under-recognized. \\
\hline Gender Ratio & Males \\
\hline Age predilection & Between 18 and 70. \\
\hline $\begin{array}{l}\text { Treatment and } \\
\text { prognosis }\end{array}$ & $\begin{array}{l}\text { - Treatment is pain-relieving for most patients. } \\
\text { - } \quad \text { NSAIDs drugs to dampen the inflammatory component and provide pain relief for the patient. } \\
\text { - } \quad \text { Eliminate risk factors: any object that rests on the suprapubic region, tool belts, money belts, and } \\
\text { electric guitars are just a few examples. } \\
\text { - Avoid sexual devices or practices that are capable of causing venous stasis and injury to the penis. } \\
\text { - Self-limiting within 4-6 weeks with the vessel regain permeability in } 9 \text { weeks. }\end{array}$ \\
\hline $\begin{array}{l}\text { Findings on } \\
\text { imaging }\end{array}$ & $\begin{array}{l}\text { - Diagnosis is usually made based on history and physical examination. The role of imaging in } \\
\text { Mondor's disease is to identify the intravascular thrombus. Grey scale and Doppler ultrasound can } \\
\text { be useful in case of diagnostic uncertainty. } \\
\text { Color-Doppler-Ultrasound: } \\
\text { - Extent of thrombosis } \\
\text { - Echogenic material within venous lumen, } \\
\text { O Impossibility of vessel compression and absence of flow } \\
\text { O Painful selective pressure. } \\
\text { - The caliber of the vein can be increased with inflammatory changes in the wall. } \\
\text { MRI: role is controversial. The signal intensity of venous varies according to the time delay } \\
\text { between the onset of thrombus formation and imaging. } \\
\text { In the acute stage (0-5 days) the signal intensity is predominantly isointense on T1- } \\
\text { weighted images and hypointense on T2-weighted images. } \\
\text { In the subacute stage (6-15 days), the signal intensity is described as predominantly } \\
\text { hyperintense on both T1- and T2-weighted images. } \\
\text { Finally, the signal intensity in a chronic thrombus is typically isointense on T1-weighted } \\
\text { and isointense or hyperintense on T2-weighted images. In a 3D fast gradient-echo dynamic } \\
\text { investigation a filling defect of the vein can be visible. } \\
\text { CT: not indicated. Basic CT aspect of a thrombophlebitis of the dorsal vein of the penis presents as a } \\
\text { thickening and hyperdensity of the vein, associated with edematous hyperdensity of the adjacent } \\
\text { subcutaneous tissue. }\end{array}$ \\
\hline
\end{tabular}

Table 2: Summary table for penile Mondor's disease.

\section{ABBREVIATIONS}

MRA = Magnetic Resonance Angiography

MRI = Magnetic Resonance Imaging

$\mathrm{CT}=$ Computed Tomography

NSAIDs $=$ non-steroidal anti-inflammatory drugs.

PMD = Penile Mondor's Disease

\section{KEYWORDS}

Penile Mondor's disease; Dorsal penis vein thrombosis; Color Doppler ultrasound; Computed Tomography

\section{Online access}

This publication is online available at: www.radiologycases.com/index.php/radiologycases/article/view/3926

\section{Peer discussion}

Discuss this manuscript in our protected discussion forum at: www.radiolopolis.com/forums/JRCR

\section{Interactivity}

This publication is available as an interactive article with scroll, window/level, magnify and more features. Available online at www.RadiologyCases.com

\section{Published by EduRad}

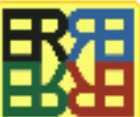

www.EduRad.org 